\title{
RESEARCH
}

Open Access

\section{Bone marrow mesenchymal stem cells transfer in patients with ST-segment elevation myocardial infarction: single- blind, multicenter, randomized controlled trial}

Runfeng Zhang ${ }^{1}$, Jiang Yu ${ }^{2}$, Ningkun Zhang ${ }^{3}$, Wensong Li ${ }^{2}$, Jisheng Wang ${ }^{1}$, Guocai Cai ${ }^{1}, Y u$ Chen ${ }^{3}$, Yong Yang ${ }^{4}$ and Zhenhong Liu ${ }^{1 *}$

\begin{abstract}
Objective: Our aim was to evaluate the efficacy and safety of intracoronary autologous bone marrow mesenchymal stem cell (BM-MSC) transplantation in patients with ST-segment elevation myocardial infarction (STEMI).

Methods: In this randomized, single-blind, controlled trial, patients with STEMI (aged 39-76 years) were enrolled at 6 centers in Beijing (The People's Liberation Army Navy General Hospital, Beijing Armed Police General Hospital, Chinese People's Liberation Army General Hospital, Beijing Huaxin Hospital, Beijing Tongren Hospital, Beijing Chaoyang Hospital West Hospital). All patients underwent optimum medical treatment and percutaneous coronary intervention and were randomly assigned in a 1:1 ratio to BM-MSC group or control group. The primary endpoint was the change of myocardial viability at the 6th month's follow-up and left ventricular (LV) function at the 12th month's follow-up. The secondary endpoints were the incidence of cardiovascular event, total mortality, and adverse event during the 12 months' follow-up. The myocardial viability assessed by single-photon emission computed tomography (SPECT). The left ventricular ejection fraction (LVEF) was used to assess LV function. All patients underwent dynamic ECG and laboratory evaluations. This trial is registered with ClinicalTrails.gov, number NCT04421274.

\footnotetext{
* Correspondence: hzljiayou@126.com

'Department of Cardiology, Department of Clinical Pharmacy, The Third Hospital of Mianyang/Sichuan Mental Health Center, Mianyang 621000, Sichuan, China

Full list of author information is available at the end of the article
}

C C The Author(s). 2021 Open Access This article is licensed under a Creative Commons Attribution 4.0 International License, which permits use, sharing, adaptation, distribution and reproduction in any medium or format, as long as you give appropriate credit to the original author(s) and the source, provide a link to the Creative Commons licence, and indicate if changes were made. The images or other third party material in this article are included in the article's Creative Commons licence, unless indicated otherwise in a credit line to the material. If material is not included in the article's Creative Commons licence and your intended use is not permitted by statutory regulation or exceeds the permitted use, you will need to obtain permission directly from the copyright holder. To view a copy of this licence, visit http://creativecommons.org/licenses/by/4.0/. The Creative Commons Public Domain Dedication waiver (http://creativecommons.org/publicdomain/zero/1.0/) applies to the data made available in this article, unless otherwise stated in a credit line to the data. 
(Continued from previous page)

Results: Between March 2008 and July 2010, 43 patients who had underwent optimum medical treatment and successful percutaneous coronary intervention were randomly assigned to BM-MSC group $(n=21)$ or control group $(n=22)$ and followed-up for 12 months. At the 6th month's follow-up, there was no significant improvement in myocardial activity in the BM-MSC group before and after transplantation. Meanwhile, there was no statistically significant difference between the two groups in the change of myocardial perfusion defect index $(p=0.37)$ and myocardial metabolic defect index $(p=0.90)$. The LVEF increased from baseline to 12 months in the BM-MSC group and control group (mean baseline-adjusted BM-MSC treatment differences in LVEF 4.8\% (SD 9.0) and mean baseline-adjusted control group treatment differences in LVEF 5.8\% (SD 6.04)). However, there was no statistically significant difference between the two groups in the change of the LVEF $(p=0.23)$. We noticed that during the 12 months' follow-up, except for one death and one coronary microvascular embolism in the BM-MSC group, no other events occurred and alanine transaminase (ALT) and C-reactive protein (CRP) in BM-MSC group were significantly lower than that in the control group.

Conclusions: The present study may have many methodological limitations, and within those limitations, we did not identify that intracoronary transfer of autologous BM-MSCs could largely promote the recovery of LV function and myocardial viability after acute myocardial infarction.

Keywords: Mesenchymal stem cells, Bone marrow, Stem cells transplantation, Myocardial infarction

\section{Introduction}

Acute myocardial infarction (AMI) is a disease in which the coronary arteries suddenly interrupt the blood flow to the heart, causing acute and persistent ischemia and hypoxia in the heart, thus increasing the risk of death [1]. AMI is further divided into two subcategories: STsegment elevation myocardial infarction (STEMI) and non-ST-segment elevation myocardial infarction (NSTE MI). STEMI is characterized by persistent typical ischemic chest pain and elevated serum myocardial necrosis markers, as well as typical ST-segment elevation of ECG [2-4], approximately accounting for $25-40 \%$ of AMI. Although most patients with STEMI can undergo percutaneous coronary intervention (PCI) and take the drugs recommended by the guidelines to relieve their symptoms, it cannot rescue the apoptotic and necrotic cardiomyocytes [5]. According to statistics, the risk of inhospital death of AMI patients has not decreased significantly in the past 10 years [6], and the number of AMI patients in China will increase to 23 million by 2030 [7].

Increasing evidence indicates that stem cells have the ability of multi-directional differentiation, and it is getting more and more attention that stem cell transplantation serves as a new alternative therapy in repairing damaged myocardium [8]. For example, pluripotent stem cells, adult tissue stem/progenitor cells including endothelial progenitor cells, skeletal muscle myoblasts, cardiac stem/progenitor cells, and bone marrow mononuclear cells have been reported to participate in the treatment of damaged cardiomyocytes [9]. In addition, it was found that these cells can repair damaged myocardium through paracrine [10].

Bone marrow mesenchymal stem cells (BM-MSCs) are the most widely studied MSC types. Many experimental studies have shown that BM-MSCs can improve heart function after AMI [11-13]. Although BM-MSCs are not abundant in bone marrow nucleated cells, accounting for only $0.01 \%$, they can be expanded one billion times in vitro without losing stem cell activity [14]. It had been found that BM-MSCs not only differentiated into cardiomyocytes to promote cardiomyocyte regeneration when they were transplanted into the heart in vivo $[15,16]$, but also secreted growth factors, cytokines, chemokines, and microRNAs to improve tissue microenvironment and effectively reduce the adverse remodeling and inflammation of cardiomyocytes. Additionally, the secreted proteins of BM-MSCs have immunosuppressive properties by regulating $\mathrm{T}$ cells, B cells, and monocytes [17-20]. Clinically, autologous bone marrow MSCs have been adopted to treat myocardial infarction by transplanting after the expansion [7]. However, reviewed from the clinical study of BM-MSCs on AMI from 2004 to 2017, it was found that only two clinical research results showed that BM-MSCs can increase the left ventricular ejection fraction of patients compared with the control group [21]. Based on existing experimental and clinical data, the best time for transplantation was 7 to 14 days after acute myocardial infarction [22-24], and it took at least 14 days to cultivate the BM-MSC seed cells. Therefore, we select to perform BM-MSC transplantation within 1 month after PCI. We chose to use BM-MSC injection with independent intellectual property rights in China to conduct a randomized, single-blind, parallelcontrolled multicenter clinical trial to observe the effectiveness and security of BM-MSC transplantation in the treatment of acute myocardial infarction. It is hoped that this study will show whether BM-MSC injection transplantation is effective and safe in patients with STEMI and provide a reliable basis for clinical promotion. 


\section{Methods}

\section{Participants}

This study is a randomized single-blind, parallelcontrolled multicenter clinical trial that started in March 2008 and ended in July 2010. A total of 43 patients came from 6 hospitals in Beijing (The People's Liberation Army Navy General Hospital, Beijing Armed Police General Hospital, Chinese People's Liberation Army General Hospital, Beijing Huaxin Hospital, Beijing Tongren Hospital, Beijing Chaoyang Hospital West Hospital), including 39 males and 4 females. Their age ranged from 39 to 76 years, with an average age of $58.9 \pm 11$ years. Based on the agreement of the Center Clinical Trial Ethics Committee and the Helsinki Declaration, we came to the research protocol as shown in Fig. 1. The standards of getting enrolled are STEMI patients, older than 18 years, who had an onset time of less than 1 month and was successfully revascularized with infarct-related vascular blood flow returning to TIMI level 3. All patients enrolled in the study signed an informed consent form and promised to complete all follow-up plans. Exclusion criteria include the following eight items: (1) patients with refractory persistent ventricular tachycardia; (2) patients with high heart block and not controlled by pacemaker; (3) patients with hepatic or kidney dysfunction (ALT > $80 \mathrm{U} / \mathrm{L}$, creatinine $(\mathrm{Cr})>440 \mathrm{mmol} / \mathrm{L}$ ); (4) patients with bleeding disorders or malignant tumors; (5) patients with autoimmune diseases or any serious fatal disease; (6) patients with contraindications for coronary intervention; (7) patients with the following other heart diseases: congenital heart disease (such as ventricular defect, atrial defect, patent ductus arteriosus), primary heart valve disease, active myocarditis, pulmonary heart disease, hyperthyroid heart disease, mucoedema heart disease, etc.; and (8) patients with mental illness, no selfawareness, and no precise expression and cooperation.

\section{Randomization and study treatment}

Participants' random numbers were generated by the network, and technical services were provided by the China Cardiovascular and Cerebrovascular Diseases Professional Network (CCVD), which was not related to this clinical trial. The participant's information was input into the computer. If the patient met the inclusion criteria, the system would give a random number and grouping to determine the randomization of the patient. The 43 patients were randomly divided into a cell transplantation group (BM-MSC injection via coronary artery perfusion, $n=21$ ) and a control group (all other treatments except cell transplantation were the same as the cell transplantation group, $n=22$ ). Because of ethical considerations, we decided not to conduct bone marrow aspiration and left heart catheterization in patients randomized to the control group. Those who were

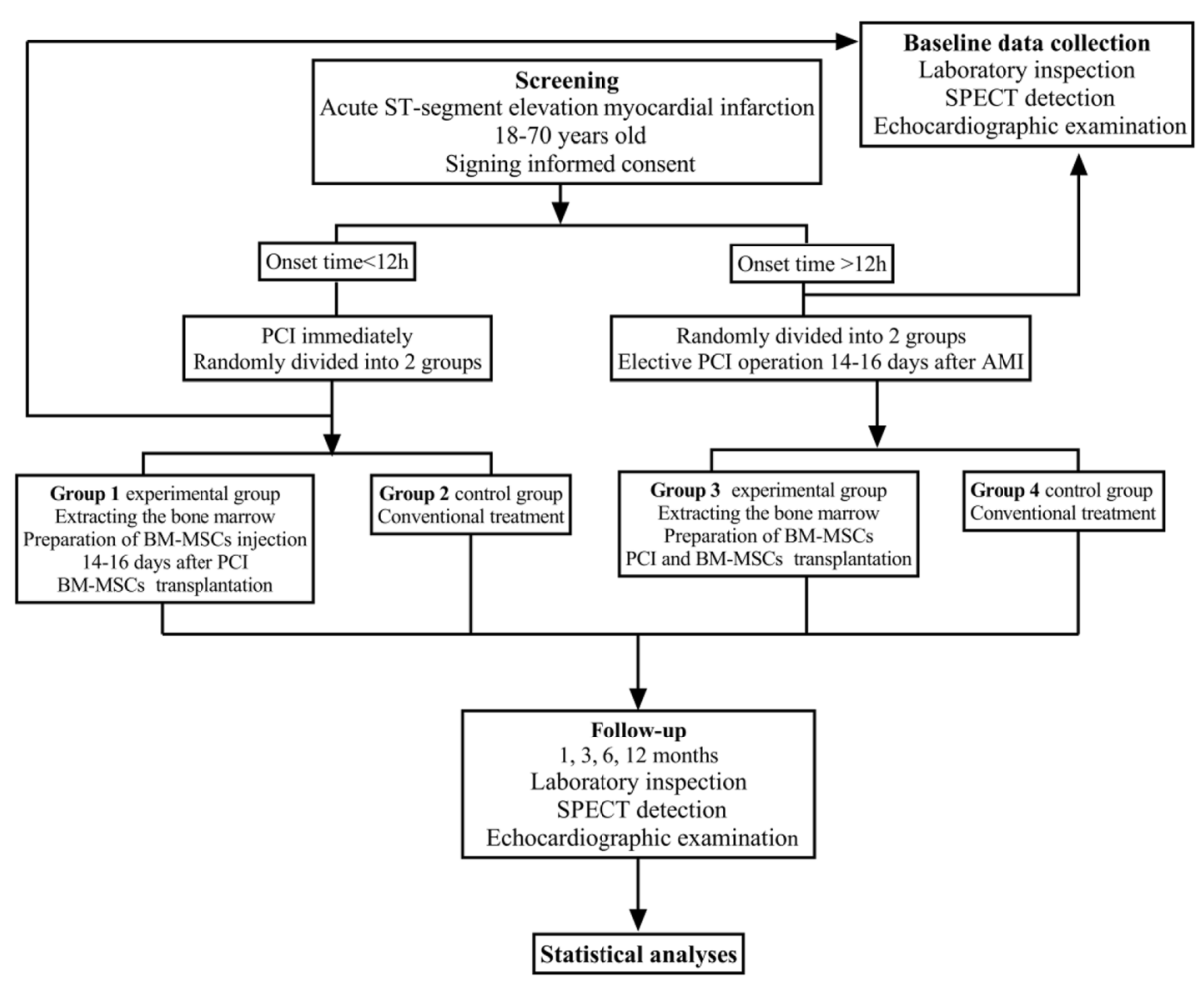

Fig. 1 Research protocol 
unsuccessful in revascularization were withdrawn from this study.

\section{Preparation of BM-MSC injection}

The collection and separation of bone marrow are performed in a sterile room. Under lidocaine local anesthesia, $80 \mathrm{ml}$ of bone marrow was extracted from the patient's posterior superior iliac crest and placed in $2000 \mathrm{IU}$ heparin saline. The BM-MSC injection was prepared by the Stem Cell and Regenerative Medicine Center of the Institute of Field Transfusion of the Academy of Military Medical Sciences according to standard procedures. Firstly, the extracted bone marrow was subjected to natural sedimentation, low-temperature centrifugation, saline washing, resuspension, counting, and Percoll centrifugation to obtain mononuclear cells. Then, mononuclear cells were cultured in DMEM medium with $10 \%$ fetal bovine serum to obtain BM-MSCs, and they were subcultured when the stem cells grew to $80 \%$ confluence. Next, take the cells after the 2-3 subculture and expansion for $72 \mathrm{~h}$, and at the same time, take the culture supernatant for bacteria, mold, and mycoplasma identification tests. The next step was to digest the cells with $0.25 \%$ trypsin at $37^{\circ} \mathrm{C}$. After repeated washing with normal saline for 3 times, we then calculated the cell concentration, the ratio of living cells, and verified the cell phenotype. Finally, resuspend the cells with $2 \mathrm{ml}$ of normal saline for injection, place them in a 2 -ml vial, and mark the patient's name and product number to ready for transplantation. The specification of this product was $1.0 \sim 2.5 \times 10^{6} \mathrm{BM}-\mathrm{MSCs} / 2 \mathrm{ml}, 2.0 \mathrm{ml} /$ bottle. During the operation, $4 \mathrm{ml}$ of BM-MSC injection was diluted to $10 \mathrm{ml}$.

\section{Injection of BM-MSCs via coronary artery}

The preoperative preparation of BM-MSCs undergoing coronary artery transplantation is the same as PCI. $14.07 \pm 9.53$ days after PCI, firstly, the patient was inserted with an ultra-long guide wire and inserted into the guide wire balloon catheter (OTW balloon) along the extra-long guide wire to the distal end of the stent. Then, pull out the guide wire and inflate the balloon pressure until there is no forward blood flow in the target vessel (balloon inflation period). Finally, to facilitate the transplantation of cells through the endothelial channel and migration into the infarcted zone, when the target vessel was completely occluded, $2 \mathrm{ml}$ of BM-MSC suspension was infused by high-pressure injection directly into the necrotic area along the central lumen of the guidewire balloon catheter. During the operation, the balloon was kept inflated for $2 \mathrm{~min}$ at a time to block the blood flow; the transplanted cells were not washed away immediately under these conditions, and then the perfusion was restored for $2 \mathrm{~min}$ to reduce the likelihood of ischemia to a minimum [23]. The above process was repeated 6 to 8 times, and the patient did not undergo angiography again after the stem cell implantation. Patients were monitored for chest pain, changes in ECG, and intracavitary pressure changes during surgical procedures.

\section{Echocardiographic examination}

The subjects underwent echocardiographic examinations before and 12 months after the operation, and the left ventricular end-diastolic volume, end-systolic volume, and ejection fraction was measured by the Simpson method. The color heart ultrasound system (GE, USA) uses VIVID7, the probe is $\mathrm{S} 4$, and the frequency is $2 \sim 4 \mathrm{MHz}$. We would collect four standard two-dimensional images (the parasternal long axis and short axis, apical two-chamber and four-chamber view).

\section{Myocardial perfusion-metabolic imaging examination}

The purpose of cardiac perfusion-metabolic imaging was to evaluate the nature of left ventricular myocardial perfusionmetabolic defects (reversible defects, fixed defects) and changes in area before and after BM-MSC transplantation. The SPECT image was divided into 20 segments, and the score was determined according to the degree of attenuation of myocardial nuclide uptake in each segment $(0$ points $=$ adequate intake, 1 point $=$ slight decrease in intake, 2 points $=$ moderate reduction in intake, 3 points = reduced ingestion, 4 points = intake defect). The sum of the scores of each segment was obtained to quantify the evaluation index of myocardial perfusion-metabolic defect, that is, the higher the value, the larger the range of myocardial perfusion-metabolic defect. The cardiac metabolic imaging was read by a professional nuclear medicine physician.

Patients with hyperlipidemia were treated with oral hypolipidemic drugs (inositol niacinate $0.2 \mathrm{~g}$ or reserpine) $2 \mathrm{~h}$ before the examination. If the patient had diabetes, control the food he took to a low level $1 \mathrm{~h}$ before the examination. We used the automatic blood glucose meter to measure the blood sugar. According to the patient's blood sugar situation, oral glucose or subcutaneous injection of insulin was considered for blood glucose regulation, and finally the patients' blood glucose was controlled in the range of 7.8 to $8.8 \mathrm{mmol} / \mathrm{L}$. The participants were intravenously injected with the imaging agent ${ }^{99} \mathrm{mTc}-\mathrm{MIBI} 20 \mathrm{Mci}(740 \mathrm{MBq})$ and ${ }^{18} \mathrm{~F}$-FDG $8 \sim 10$ Mci (296-370 MBq) after $30 \mathrm{~min}$ of blood glucose regulation. Myocardial perfusion-metabolic imaging was observed after $45-60 \mathrm{~min}$ of injection. The ${ }^{99} \mathrm{mTc}-\mathrm{MIBI}$ $\left({ }^{99} \mathrm{mTc}\right.$-methoxyisobutyl isonitrile) and ${ }^{18} \mathrm{~F}$-FDG $\left({ }^{18} \mathrm{~F}\right.$ deoxyglucose) was provided by Atomic High Tech of China Institute of Atomic Energy. The imaging instrument used GE's Millennium VG Hawkeye SPECT, equipped with $511 \mathrm{Kev}$ high-energy collimator and dual probes in L mode. The acquired images were processed by the ECToobox heart software, and the horizontal long-axis, vertical long-axis, short-axis images, and bullseye image were obtained after reconstruction. 


\section{Observation}

\section{Primary endpoint}

The changes of myocardial metabolic activity (SPECT detection) at the 6th month after autologous BM-MSC transplantation and the changes in left ventricular ejection fraction (LVEF) at the 12th month after transplantation of autologous BM-MSCs.

\section{Secondary endpoint}

Incidence of cardiovascular events, overall mortality, and adverse events 12 months after transplantation of autologous BM-MSCs.

\section{Evaluation index}

\section{Effective assessment of myocardial reconstruction:} assessment using cardiac metabolic imaging

The following two conditions are indispensable before BM-MSC transplantation in myocardial reconstruction can be judged to be effective: (1) the increase in 18-FDG uptake at the 6th month after BM-MSC transplantation constitutes a statistical difference with that before transplantation and (2) the increase in 18-FDG uptake at the 6th month after BM-MSC transplantation constitutes a statistical difference with the control group.

\section{Effective evaluation of improving heart function: assessment using LVEF}

The following two conditions are indispensable before BM-MSC transplantation in improving cardiac function can be judged to be effective: (1) the increase in LVEF at the 12th month after BM-MSC transplantation constitutes a statistical difference with that before transplantation and (2) the increase in LVEF at the 12th month after BM-MSC transplantation constitutes a statistical difference with the control group.

The safety was evaluated by coronary angiography, laboratory abnormalities, and the incidence of adverse events during the 12 months' follow-up.

\section{Statistical analyses}

Statistical analysis was performed with SPSS17.0 software. The measurement data were expressed as mean \pm standard deviation (mean $\pm \mathrm{SD}$ ), and the comparison of means between the two groups was analyzed by $t$ test; $P<0.05$ was considered a significant difference.

\section{Result}

\section{Research protocol}

\section{Patient characteristics}

The enrollment and outcomes of the patients are shown in Fig. 2. In the BM-MSC transplantation group, 19 patients completed a 6-month follow-up and 18 patients completed a 1-year follow-up. In the control group, 21 patients completed a 6-month follow-up, and 19 patients completed a 1-year follow-up. One case in each group did not involve in the 6-month follow-up for the

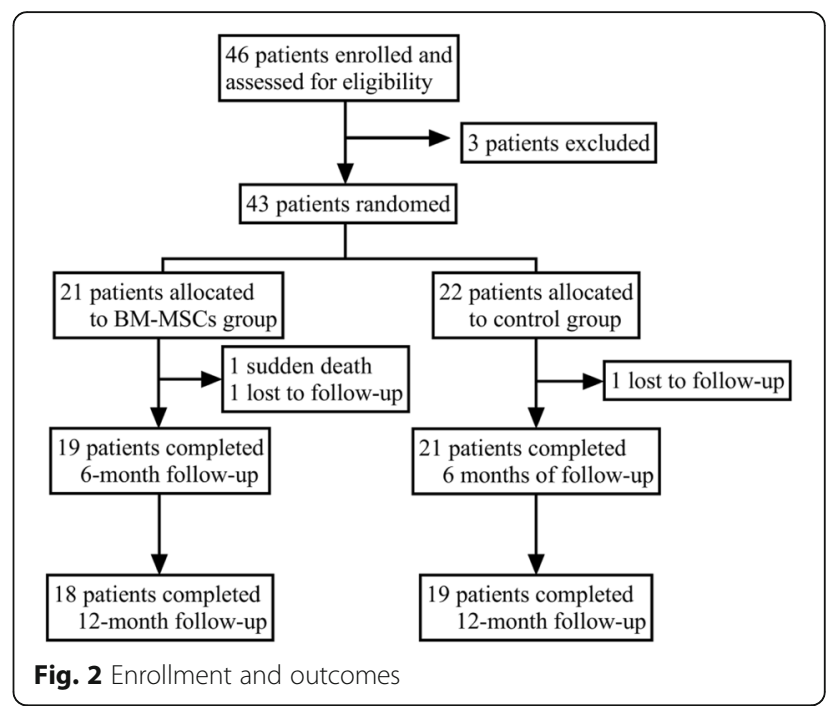

patients' emigration. One patient died in the BM-MSC transplantation group. For patients with acute myocardial infarction $<12 \mathrm{~h}$, baseline data were collected after direct PCI, before BM-MSC transplantation, and the patient's condition was stable. For onset $>12 \mathrm{~h}$, the baseline data were collected before PCI. There were no significant differences between the baseline clinical characteristics of the two groups of subjects (Table 1).

\section{Comparison of echocardiographic parameters before and} after surgery in two groups

There was no significant difference in left ventricular end-systolic volume (LVESV), left ventricular enddiastolic volume (LVEDV), and LVEF between the two groups at baseline $(P>0.05)$. After 12 months, the LVESV, LVEDV and LVEF in the BM-MSCs group was significantly improved compared with that before transplantation. The control group also showed the same results as the BM-MSC group, but there was no significant differences in LVESV, LVEDV, and LVEF improvement in two groups $(P>0.05)$ (Table 2, Figs. 3, 4 , and 5).

\section{Comparison of myocardial perfusion and metabolic activity between the two groups}

The myocardial perfusion and metabolic defect index at baseline of the two groups of patients was similar $(P>$ $0.05)$. There was no significant difference between the two groups before and after treatment $(P>0.05)$. Compared with the control group, the myocardial perfusion and metabolic defect in the BM-MSC transplantation group did not improve after 6 months $(P>0.05)$, suggesting that the infarcted myocardium was not effectively replaced or repaired (Table 3, Figs. 6, 7, 8, and 9). 
Table 1 Baseline characteristics of the study population

\begin{tabular}{|c|c|c|c|}
\hline & BM-MSCs $(\mathrm{n}=21)$ & Control $(\mathrm{n}=22)$ & $P$ value \\
\hline Age (years) & $59.3 \pm 9$ & $58.6 \pm 11$ & NS \\
\hline Sex (male/female) & $20 / 1$ & $19 / 3$ & NS \\
\hline Body mass index $\left(\mathrm{kg} / \mathrm{m}^{2}\right)$ & $28.3 \pm 3.3$ & $28.5 \pm 3.7$ & NS \\
\hline Dyslipidemia (case) & 6 & 7 & NS \\
\hline Diabetes mellitus (case) & 8 & 5 & NS \\
\hline Hypertension (case) & 13 & 11 & NS \\
\hline Current smoker (case) & 8 & 6 & NS \\
\hline Family history of coronary artery disease (case) & 9 & 9 & NS \\
\hline Previous myocardial infarction (case) & 0 & 0 & NS \\
\hline Previous percutaneous coronary intervention (case) & 0 & 0 & NS \\
\hline \multicolumn{4}{|l|}{ Infarct related artery } \\
\hline Left anterior descending (case) & 13 & 11 & NS \\
\hline Left circumflex artery (case) & 1 & 2 & NS \\
\hline Right coronary artery (case) & 7 & 9 & NS \\
\hline Syntax score & $22.21 \pm 11.71$ & $23.5 \pm 4.77$ & NS \\
\hline \multicolumn{4}{|l|}{ Killip } \\
\hline Class I (case) & 7 & 5 & NS \\
\hline Class II (case) & 10 & 13 & NS \\
\hline Class III (case) & 3 & 4 & NS \\
\hline Class IV (case) & 1 & 0 & NS \\
\hline LVEF (\%) & $57.2 \pm 10.2$ & $53.7 \pm 6.4$ & 0.18 \\
\hline \multicolumn{4}{|l|}{ Pre-PCI TIMI blood flow } \\
\hline Class 0 or I & 19 & 21 & NS \\
\hline Class II & 2 & 1 & NS \\
\hline Class III & 0 & 0 & NS \\
\hline Plasma CK peak (U/L) & $2516 \pm 1007$ & $2638 \pm 1598$ & NS \\
\hline Plasma CK-MB peak (U/L) & $97 \pm 33$ & $105 \pm 41$ & NS \\
\hline Plasma cTnI peak (ng/ml) & $10.9 \pm 9.7$ & $11.1 \pm 10.5$ & NS \\
\hline Systolic pressure at admission & $141 \pm 23$ & $139 \pm 21$ & NS \\
\hline Diastolic pressure at admission & $83 \pm 16$ & $81 \pm 14$ & NS \\
\hline Pre-PCI thrombolysis & 0 & 1 & NS \\
\hline Pre-PCI GPIIb/IIIa blocker & 15 & 18 & NS \\
\hline \multicolumn{4}{|l|}{ Drugs } \\
\hline Aspirin & 21 & 22 & NS \\
\hline Clopidogrel & 21 & 22 & NS \\
\hline Beta blocker & 17 & 19 & NS \\
\hline Nitrate & 21 & 22 & NS \\
\hline ACEI & 17 & 17 & NS \\
\hline ARB & 3 & 5 & NS \\
\hline Statins & 21 & 22 & NS \\
\hline
\end{tabular}

\section{Follow-up results and safety assessment}

During the follow-up period, the types and numbers of arrhythmias detected by Holter were similar in the two groups (Table 4). In the BM-MSC group, there was no significant difference in blood leukocyte (WBC), Cr, and carcinoembryonic antigen before and after transplantation, and ALT and CRP were significantly decreased (Table 5). There was no statistical difference between the BM-MSC group and the control group in the above laboratory examination indexes after the end of the experiment (Table 6).

There were no adverse reactions such as stent thrombosis, recurrence of myocardial infarction, malignant arrhythmia, tumor, and myocardial fibrosis in the two groups of patients during the peri-treatment period. One case of sudden death in the BM-MSC group and one patient occurred microvascular embolism (Table 7).

Table 2 Comparison of cardiac function between BM-MSC group and control group

\begin{tabular}{lcccc}
\hline & \multicolumn{3}{c}{ Baseline } & \multicolumn{2}{c}{12 months } \\
\hline & $\begin{array}{c}\text { Control } \\
(\mathrm{n}=22)\end{array}$ & $\begin{array}{c}\text { BM-MSCs } \\
(\mathrm{n}=21)\end{array}$ & $\begin{array}{c}\text { Control } \\
(\mathrm{n}=19)\end{array}$ & $\begin{array}{c}\text { BM-MSCs } \\
(\mathrm{n}=18)\end{array}$ \\
$\operatorname{LVESV}(\mathrm{ml})$ & $73.8 \pm 14.3$ & $72.8 \pm 19.6$ & $63.0 \pm 15.4$ & $65.8 \pm 20.8$ \\
$\operatorname{LVEDV}(\mathrm{ml})$ & $141.8 \pm 18.8$ & $141.8 \pm 18.1$ & $126.4 \pm 13.7$ & $130.3 \pm 15.0$ \\
LVEF $(\%)$ & $53.7 \pm 6.4$ & $57.2 \pm 10.2$ & $59.5 \pm 5.6$ & $62.0 \pm 6.8$ \\
\hline
\end{tabular}



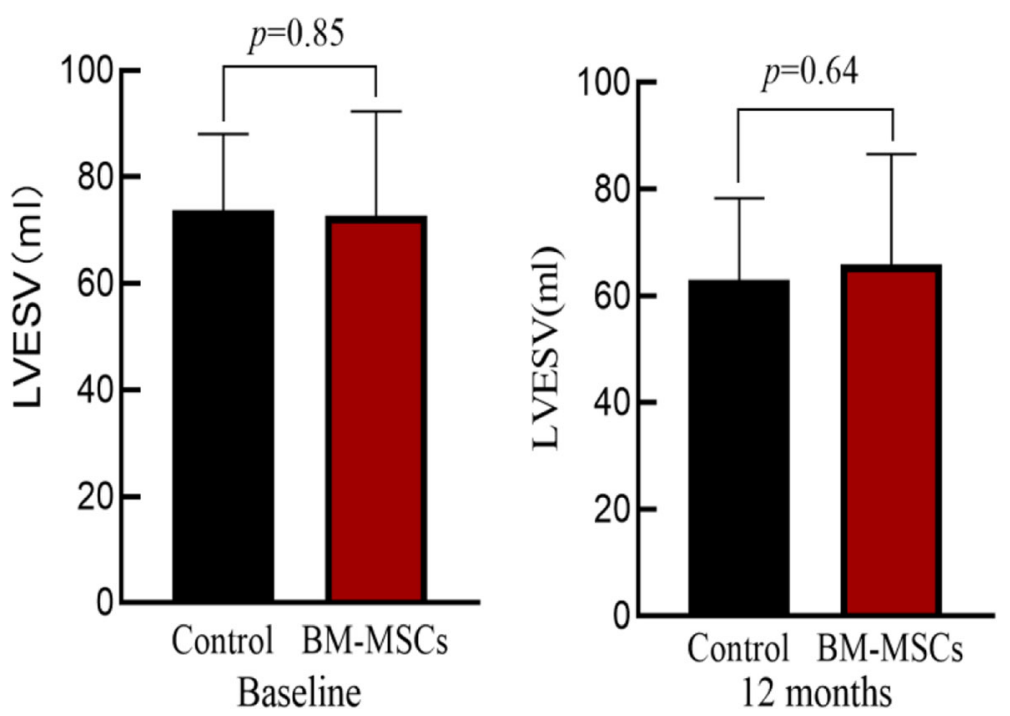

Fig. 3 LVESV comparison

\section{Discussion}

In the field of clinical research on stem cells, there are different reports on the types of transplanted cells, and there are also differences in the results of BM-MSCs cell transplantation on the improvement of cardiac function in clinical studies. In this study, autologous BM-MSCs (prepared uniformly by the Stem Cell and Regenerative Medicine Center of the Field Transfusion Institute of the Academy of Military Medical Sciences) were selected and transplanted into the heart after infarction by intracoronary injection. The effect and safety of the transplantation were observed. The results showed that compared with the control group, the 6-month metabolic imaging defect score of the BM-MSC transplantation patients was not statistically significant, and the 12-month left ventricular ejection fraction did not constitute a statistically significant improvement. The reasons for the above results are as follows:

(1) It is related to the insufficient number of the enrolled patients. The number of selected cases was determined on the basis that the differences between the different treatment groups when the primary endpoint which is expected to reach is 4 to $5 \%$. If the difference between the different
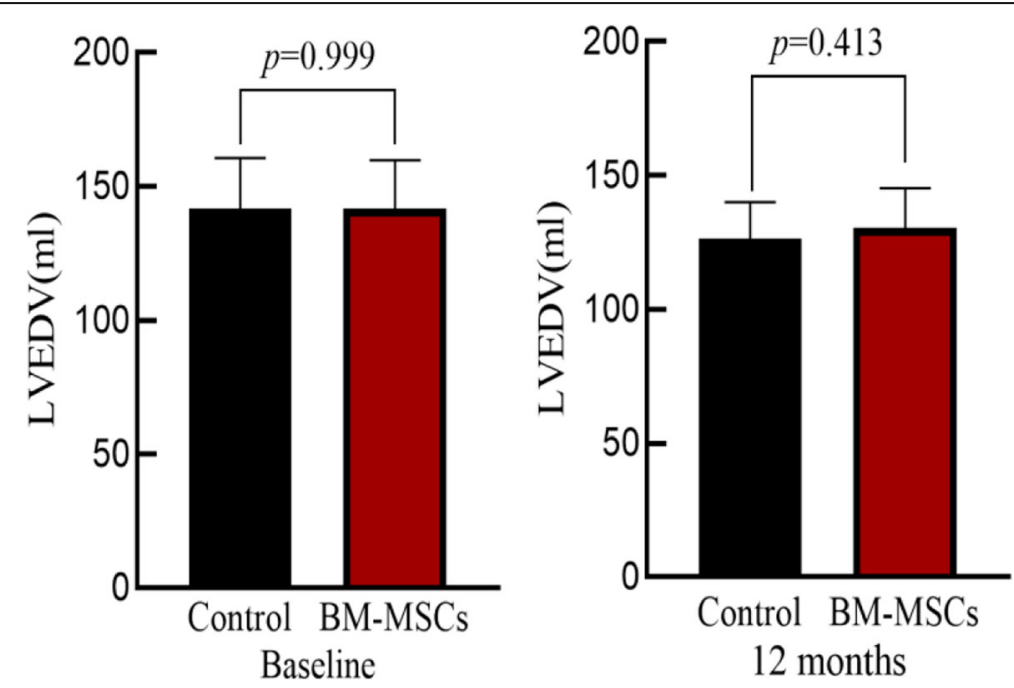

Fig. 4 LVEDV comparison 

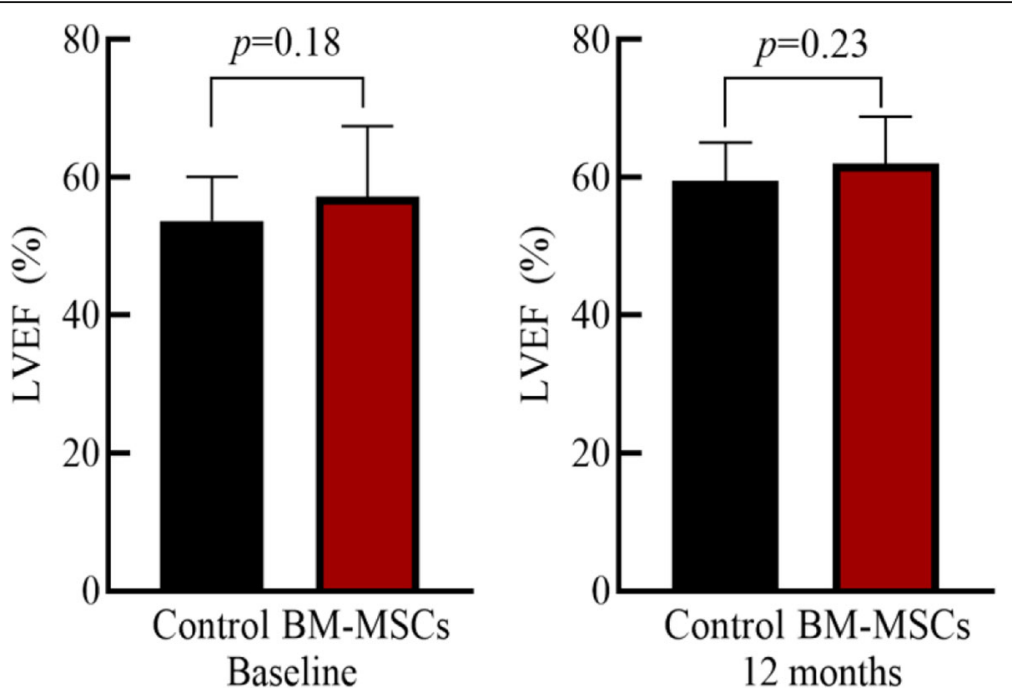

Fig. 5 LVEF comparison

treatment groups was $4.5 \%$, the bilateral test was carried out at a significant level of $\alpha=0.05$, and the test efficacy reached $80 \%$. To draw a conclusion, the difference was statistically significant; then, 34 patients were required in each group [25]. Our initial trial design plan was to distribute the group serial numbers to 6 research centers to ensure that there are at least 240 clinically valid cases (120 pairs) at the end of the experiment. Each trial center has completed at least 40 clinically valid cases (20 pairs). During the implementation of this study, it was discovered that although the researchers explained in detail to the patients that the extraction of bone marrow had no adverse effects on the body, the patient had an instinctive fear of taking bone marrow, and they were very resistant. In addition, since this study was an innovative clinical trial, the postoperative efficacy was unknown. In this study, therefore, the number of patients we recruited was limited-only 43 patients had been eventually enrolled in 6 hospitals over the past 2 years, and the number of cases was seriously insufficient.

(2) It is related to insufficient dose of transplanted cells. The number and function of autologous bone marrow MSCs decrease with age [26]; 80 $\mathrm{ml}$ bone marrow was extracted from the patient, extracted, cultured, and expanded for 2 weeks $(13.89 \pm 1.60$ days $)$ to obtain $1 \sim 2.5 \times 10^{6} \mathrm{BM}-$ MSCs. At the same time, considering that highdose cell transplantation may cause embolization of distal blood vessels [27], we chose low-dose cell transplantation $\left(3.31 \pm 1.70 \times 10^{6}\right.$ cells $)$. The number of cells may not reach the therapeutic dose. Perin et al. [28] compared the effects of three doses $\left(25,75\right.$, or $150 \times 10^{6}$ cells) of allogeneic BM-MSCs on adverse cardiac events and left ventricular remodeling. The results showed that the higher the dose of BM-MSCs, the fewer adverse cardiac events, the lesser the degree of left ventricular remodeling. In addition, the TRID ENT trial found that compared with the lower dose of BM-MSCs $\left(20 \times 10^{6}\right.$ cells $)$, the higher

Table 3 Comparison of static myocardial perfusion-metabolic defect index before and after treatment in BM-MSC transplantation group and control group

\begin{tabular}{lcccc}
\hline & \multicolumn{2}{c}{ Baseline } & \multicolumn{2}{c}{6 months } \\
\hline & $\begin{array}{c}\text { Control } \\
(n=22)\end{array}$ & $\begin{array}{c}\text { BM-MSCs } \\
(n=21)\end{array}$ & $\begin{array}{c}\text { Control } \\
(n=21)\end{array}$ & $\begin{array}{c}\text { BM-MSCs } \\
(n=19)\end{array}$ \\
Myocardial perfusion defect index $(\%)$ & $21.0 \pm 5.5$ & $21.9 \pm 6.1$ & $18.4 \pm 4.8$ & $18.6 \pm 5.6$ \\
Myocardial metabolic defect index $(\%)$ & $23.9 \pm 5.7$ & $27.2 \pm 6.1$ & $19.9 \pm 5.2$ & $21.6 \pm 6.5$ \\
\hline
\end{tabular}



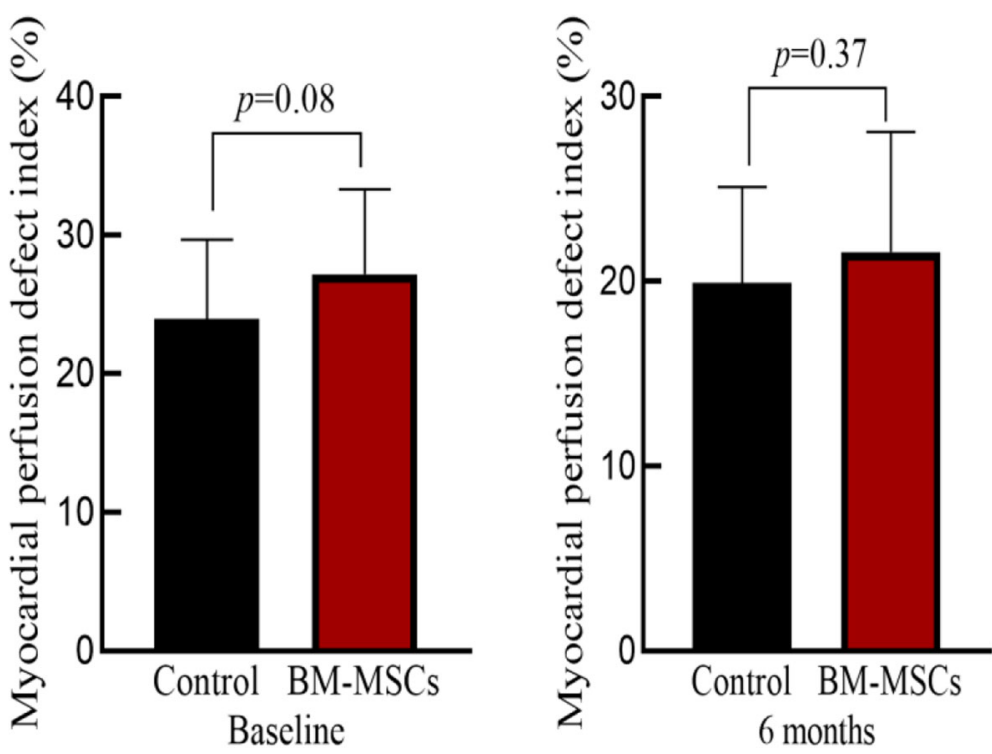

Fig. 6 Myocardial perfusion defect index

dose group of BM-MSCs $\left(100 \times 10^{6}\right.$ cells $)$ can improve LVEF and maintain the level of serum brain natriuretic peptide [29]. It is worth noting that the abovementioned experiments showed that the number of cells with significantly improved cardiac function after BM-MSC transplantation was greater than $70 \times 10^{6}$ cells.

However, the number of cells transplanted into the patient in this experiment was $3.31 \pm 1.70 \times$
$10^{6}$ cells, which was much smaller than $70 \times 10^{6}$ cells. Therefore, compared with the control group, the experimental group was more likely to have a negative result.

(3) The optimal time window for cell transplantation may have been missed. The appropriate time for stem cell transplantation should be after the inflammatory response and before the scar extension. Premature transplantation may result in

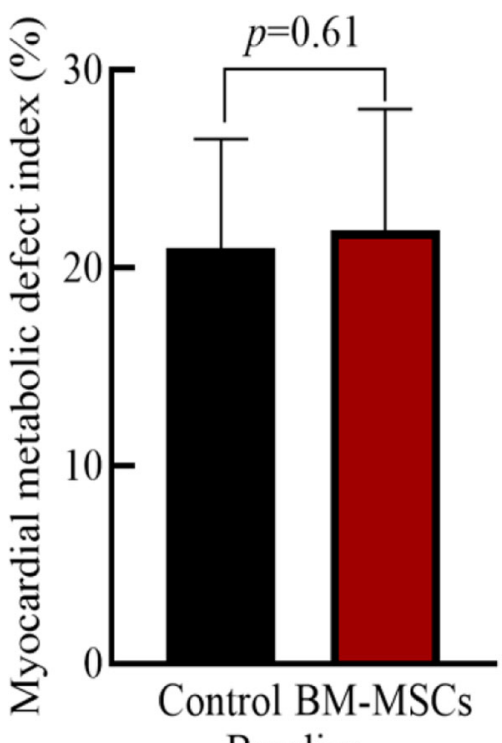

Baseline

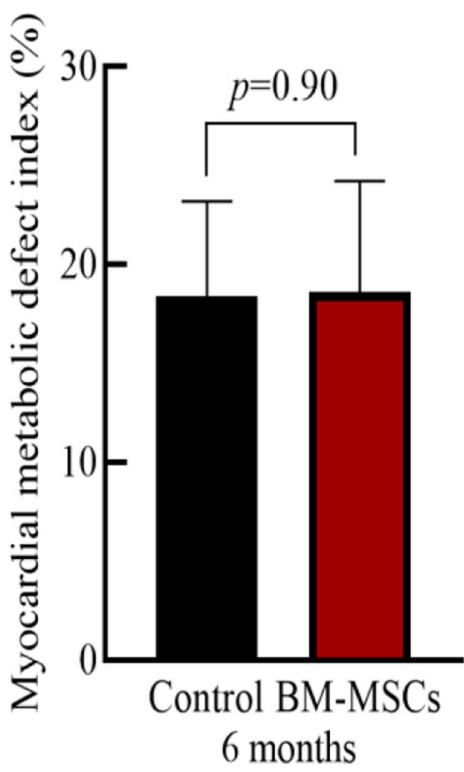

Fig. 7 Myocardial metabolic defect index 


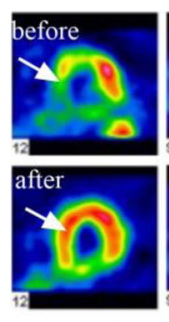

short-axis

A

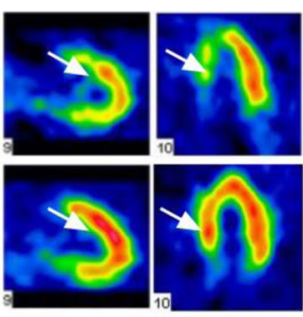

B
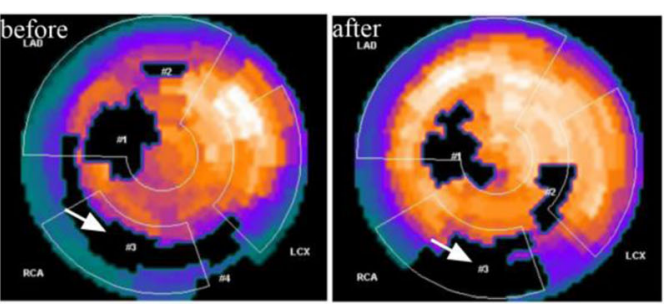

D

bull's-eye plot

C

Fig. 8 Representative ${ }^{99} \mathrm{mTc}-\mathrm{MIBI}$ positron emission tomograms in a short-axis view, b vertical long-axis view, $\mathbf{c}$ horizontal long-axis view, and $\mathbf{d}$ bull's-eye view. Before operation, the multiple areas showed persistent defects (arrows). Six months after cell transplantation, the same area show a restoration of ${ }^{99} \mathrm{mTc}-\mathrm{MIBI}$ uptake, suggesting a return of the myocardial blood perfusion with increased tracer intensity in the infarcted area after versus before cell infusion

the death of a large number of transplanted cells due to the poor local microenvironment, which may affect the transplantation effect. If transplantation is too late, local damage may be irreversible and ventricular remodeling may have been formed [30]. Previous clinical research data suggest that the clinical research of intracoronary stem cell injection therapy should be conducted 7 to 14 days after acute myocardial infarction [22-24]. However, the culture of BM-MSCs in this experiment required at least 14 days, thus the stem cell transplantation time was $14.07 \pm 9.53$ days after PCI and 23.24 \pm 7.69 days after myocardial infarction, which was beyond the operating time range for obtaining positive experimental results. In addition, some scholars believe that the best time for stem cell transplantation is 4 7 days after the onset time of STEMI [31]. The latest meta-analysis results also show that [32] the optimal time window for BMMSC transplantation was within 1 week after PCI. However, Kim et al. [33] transplanted autologous
BM-MSCs $30 \pm 1.3$ days after PCI and found that compared with the control group, the BM-MSC group can significantly increase the left ventricular ejection fraction of the patient. Therefore, further clinical randomized trials need to confirm the optimal transplant time window to treatment.

(4) It may not be the optimal way for BM-MSC transplantation in our experiments. Fukushima et al. [34] and others found that the transplantation methods of BM-MSC, such as intramyocardial injection, intracoronary injection, or intravenous injection, are not satisfactory. There is still a need to develop new and more effective cell transplantation methods, such as the use of bioengineering technology for epicardial implantation [34-36]. In this study, BMMSCs were transplanted into coronary arteries, and the number of cell survival was unknown [37], which affected the results of the experimental group.

(5) It may not be the optimal seed cell. BM-MSC is a subgroup of bone marrow stem cells with low bone

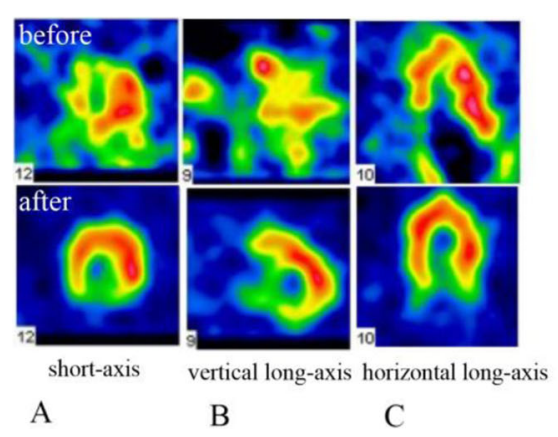

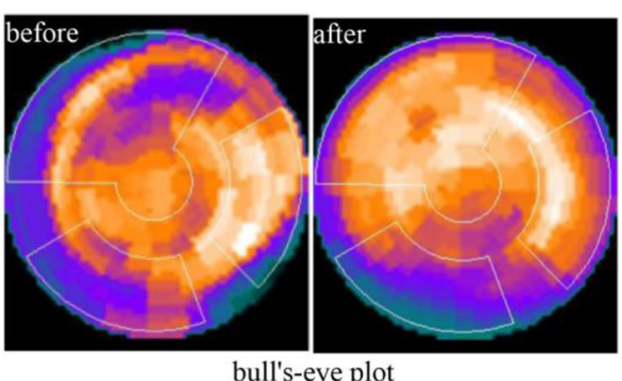

D

Fig. 9 Representative ${ }^{18}$ F-FDG positron emission tomograms in a short-axis view, b vertical long-axis view, c horizontal long-axis view, and $\mathbf{d}$ bull's-eye view. Before operation, the multiple area showed a sustained deficit. Six months after cell transplantation, the same areas show a restoration of glucose uptake, suggesting a return of myocardial viability with increased tracer intensity in the infarcted area after versus before cell infusion 
Table 4 Comparison of Holter between BM-MSC group and control group

\begin{tabular}{lcccc}
\hline & \multicolumn{2}{c}{ Baseline } & \multicolumn{2}{c}{12 months } \\
\hline & $\begin{array}{c}\text { Control } \\
(\mathrm{n}=22)\end{array}$ & $\begin{array}{c}\text { BM-MSCs } \\
(\mathrm{n}=21)\end{array}$ & $\begin{array}{c}\text { Control } \\
(\mathrm{n}=19)\end{array}$ & $\begin{array}{c}\text { BM-MSCs } \\
(\mathrm{n}=18)\end{array}$ \\
Supraventricular premature beat & $316.9 \pm 173.9$ & $310.7 \pm 155.5$ & $313.6 \pm 168.5$ & $315.7 \pm 190.3$ \\
Supraventricular tachycardia & $5.2 \pm 3.8$ & $5.3 \pm 3.4$ & $5.1 \pm 3.6$ & $4.9 \pm 3.9$ \\
Premature ventricular beat & $89.6 \pm 66.7$ & $101.4 \pm 63.8$ & $111.6 \pm 53.4$ & $99.6 \pm 70.9$ \\
Non-sustained ventricular tachycardia & $2.1 \pm 0.9$ & $2.3 \pm 0.5$ & $2.0 \pm 0.8$ & $2.5 \pm 0.8$ \\
\hline
\end{tabular}

marrow content and needs to be cultured and expanded in vitro. In particular, BM-MSCs need to be cultured for a long time, which brings about in vitro pollution; reduced homing function, large cell size, easy microthrombosis, and other undesirable factors; and reduces which their better cardiac regeneration effect. Therefore, the use of autologous bone marrow mesenchymal stem cells as seed cells for cell transplantation in this study may have great limitations and potential risks, and it is not a suitable cell type for transplantation. Current research shows that umbilical cord Wharton's jelly-derived mesenchymal stem cells (WJ-MSCs) are a group of adult stem cells that are more primitive and have stronger differentiation potential than BM-MSCs [38]. Compared with BM-MSCs, WJ-MSCs are easier to obtain in large quantities and are more primitive. They have higher separation efficiency and stronger plasticity. They are stronger in repairing myocardium, regenerating blood vessels, and improving heart function $[39,40]$. At present, many researchers believe that WJ-MSCs are true adult primitive stem cells between embryonic stem cells and adult stem cells. Several animal experiments have confirmed that WJ-MSC transplantation reduces cell apoptosis and fibrosis, strengthens viable myocardium, and improves the remodeling and function of ventricle. For example, Zhang et al. [41] evaluated the impact of WJ-MSC in a pig model of acute myocardial infarction and followed-up for 6 weeks. Lopez et al. [40], in a rat model of acute myocardial infarction, suggested that intravenous injection of WJ-MSC is more beneficial than BMMSC to improve myocardial ischemia. What is more noteworthy is that although WJ-MSCs are allogeneic seed cells, they have immunogenic characteristics different from other xenogeneic stem cells, special immunosuppressive, and immunoregulatory functions and have no immunogenicity for transplantation in vivo [42]. However, there is still a lack of clinical trials to ensure the safety and effectiveness of this seed cell.

There was no significant difference between the incidence of cardiovascular events, the total mortality, and incidence of adverse events in the BM-MSC group and the control group. One patient in the BM-MSC group had a small number of BM-MSCs, the culture time was extended to 19 days, and coronary microembolization occurred during coronary artery transplantation. The analysis may be due to the long culture time of BMMSCs, which reduces the function and quality of cells, resulting in increased volume and enhanced adhesion, resulting in microthrombosis and microvascular spasm $[43,44]$. One case of death occurred in the BM-MSC group. When the patient was admitted to the emergency department, coronary angiography showed that the culprit's blood vessels (the left anterior descending coronary artery and the left circumflex coronary artery) had a stenosis of $90 \%$ and the syntax score was 33 . Therefore,

Table 5 Changes of laboratory indexes before and after transplantation in BM-MSC group $(n=18)$

\begin{tabular}{cccc}
\hline & Baseline & 12 months & $P$ value \\
\hline WBC $\left(\times 10^{9}\right)$ & $8.3 \pm 0.8$ & $7.9 \pm 0.9$ & NS \\
ALT $(\mathrm{U} / \mathrm{L})$ & $49.7 \pm 14.5$ & $38.3 \pm 11.8$ & $<0.05$ \\
Cr $(\mu \mathrm{mol} / \mathrm{L})$ & $78.8 \pm 19.5$ & $76.5 \pm 21.6$ & $\mathrm{NS}$ \\
$\mathrm{CRP}(\mathrm{mg} / \mathrm{L})$ & $11.3 \pm 5.7$ & $5.1 \pm 4.9$ & $<0.05$ \\
\hline $\mathrm{CEA}(\mathrm{ng} / \mathrm{ml})$ & $2.3 \pm 1.7$ & $2.2 \pm 1.6$ & $\mathrm{NS}$ \\
\hline
\end{tabular}


Table 6 Comparison of laboratory indexes between BM-MSC group and control group

\begin{tabular}{lccc}
\hline & Control $(\mathrm{n}=19)$ & BM-MSCs $(\mathrm{n}=18)$ & $P$ value \\
\hline WBC $\left(\times 10^{9} / \mathrm{L}\right)$ & $7.6 \pm 0.6$ & $7.9 \pm 0.9$ & NS \\
ALT $(\mathrm{U} / \mathrm{L})$ & $33.4 \pm 10.3$ & $38.3 \pm 11.8$ & NS \\
Cr $(\mu \mathrm{mol} / \mathrm{L})$ & $73.1 \pm 16.8$ & $76.5 \pm 21.6$ & NS \\
CRP $(\mathrm{mg} / \mathrm{L})$ & $4.7 \pm 5.5$ & $5.1 \pm 4.9$ & $\mathrm{NS}$ \\
CEA $(\mathrm{ng} / \mathrm{ml})$ & $1.9 \pm 1.3$ & $2.2 \pm 1.6$ & NS \\
\hline
\end{tabular}

coronary artery bypass graft (CABG) therapy was recommended. However, after communicating with patients and their families, PCI was chosen. The patient felt tightness and moderate edema of both lower limbs after the PCI. We consider the onset of acute left heart failure. Two weeks after PCI, the patient's condition was stable. With the consent of the patient and his family, the patient received coronary BM-MSC injection therapy. The patient had no symptoms of particular discomfort during or after the BM-MSC injection therapy. Before and after the BM-MSC injection therapy, the patient tried to defecate slowly and did not want to take laxative drugs. On the third day after the operation, the patient suddenly fainted to the ground after getting up from the toilet. After discussion, the possibility of sudden cardiac death due to acute increase in cardiac load after the patient got out of bed to defecate cannot be ruled out. Unfortunately, no autopsy was performed to prove it.

The results of this study indicate that low-dose BMMSC intracoronary transplantation is not inferior to traditional standard treatment after PCI for left ventricular function and myocardial remodeling after myocardial infarction. Under the condition that the BM-MSC culture time length is appropriate, the incidence of cardiovascular events, total mortality, and incidence of adverse events in patients with ST-segment elevation myocardial infarction will not be increased.

Based on the existing reports and the results of this experiment, BM-MSC is still an important donor for AMI cell transplantation therapy. However, if BM-MSCs are to achieve better therapeutic effects in the future, it is still necessary to improve the treatment regimen to enhance the therapeutic effect, such as the use of the optimal cell dose, optimal cell transplantation method, optimal seed cell, and the improvement of cell culture protocols to expand the BM-MSCs do not lose cell function, which requires further experimental and clinical studies to determine.

\section{Conclusions}

The present study may have many methodological limitations, and within those limitations, we did not identify that intracoronary transfer of autologous BMMSCs could largely promote the recovery of LV

Table 7 Cumulative clinical events during the 12-month follow-up period in both groups

\begin{tabular}{lccc}
\hline & BM-MSCs $(\mathrm{n}=18)$ & Control $(\mathrm{n}=19)$ & $P$ value \\
\hline Death & 1 & 0 & $\mathrm{NS}$ \\
Recurrent myocardial infarction & 0 & 0 & $\mathrm{NS}$ \\
Admitted to hospital due to heart failure & 3 & 4 & $\mathrm{NS}$ \\
Revascularisation: & & \\
$\quad$ Target vessel reconstruction Stent & 0 & 0 & $\mathrm{NS}$ \\
thrombus & 0 & 0 & $\mathrm{NS}$ \\
Non-target revascularization & 5 & 7 & $\mathrm{NS}$ \\
Stroke & 0 & 0 & $\mathrm{NS}$ \\
Malignant arrhythmia/syncope & 0 & 0 & $\mathrm{NS}$ \\
Tumor & 0 & 0 & $\mathrm{NS}$ \\
Myocardial fibrosis & 0 & 0 & $\mathrm{NS}$ \\
Microvascular embolization & 1 & 0 & $\mathrm{NS}$ \\
NYHA at 1 year follow-up & $1.7 \pm 0.6$ & $1.7 \pm 0.7$ & $\mathrm{NS}$ \\
\hline
\end{tabular}




\section{function and myocardial viability after acute myocar- dial infarction.}

\section{Abbreviations}

BM-MSCs: Bone marrow mesenchymal stem cells; STEMI: ST-segment elevation myocardial infarction; NSTEMI: Non-ST-segment elevation myocardial infarction; LV: Left ventricular; SPECT: Single-photon emission computed tomography; SD: Standard difference; ALT: Alanine transaminase; CRP: C-reactive protein; AMI: Acute myocardial infarction; PCI: Percutaneous coronary intervention; CCVD: Cerebrovascular Diseases Professional Network; LVEF: Left ventricular ejection fraction; LVESV: Left ventricular end-systolic volume; LVEDV: Left ventricular end-diastolic volume; CABG: Coronary artery bypass graft

\section{Acknowledgements}

Thanks to the following 6 units of Cardiovascular and Cardiac Interventional Catheters for their support and assistance in this research: The People's Liberation Army Navy General Hospital, Beijing Armed Police General Hospital, Chinese People's Liberation Army General Hospital, Beijing Huaxin Hospital, Beijing Tongren Hospital, Beijing Chaoyang Hospital West Hospital.

\section{Authors' contributions}

Runfeng Zhang, Ningkun Zhang, Yu Chen, and Yong Yang were responsible for the preparation and characterization of BM-MSCs for transplantation. Runfeng Zhang and Jisheng Wang were responsible for the conception of the study and organization of the experimental design and coordination. Jiang $\mathrm{Yu}$, Zhenhong Liu, and Wensong Li were responsible for the writing of the manuscript. Runfeng Zhang, Jiang Yu, Ningkun Zhang, Guocai Cai, Yu Chen and Yong Yang were responsible for the critical review of all experimental data and review and revision of the final manuscript. The authors read and approved the final manuscript.

\section{Funding}

Scientific Research Projects of Sichuan Medical Planning Commission: Heart transplantation effect of stem cells-Study on Paracrine Mechanism (100306).

\section{Availability of data and materials}

The datasets used and/or analyzed during the current study are available from the corresponding author on reasonable request.

\section{Ethics approval and consent to participate}

Upon written informed consent and following the ethical principles of the Helsinki Declaration, intracoronary transplantation of bone marrow mesenchymal stem cells was completed in the cardiovascular interventional operating rooms of 6 hospitals in Beijing under Institutional Review Board approval (number 17/int/2020 approved by the Third Hospital of Mianyang Ethics Committee).

\section{Consent for publication}

$$
\text { Not applicable. }
$$

\section{Competing interests}

At the time of this study, all authors indicated no potential conflicts of interest.

\footnotetext{
Author details

'Department of Cardiology, Department of Clinical Pharmacy, The Third Hospital of Mianyang/Sichuan Mental Health Center, Mianyang 621000, Sichuan, China. ${ }^{2}$ Department of Cardiology, The Affiliated Hospital of Southwest Medical University, Luzhou 646000, Sichuan, China. ${ }^{3}$ Heart Centre, The Navy General Hospital, Beijing 100048, China. ${ }^{4}$ Department of Cardiology, The General Hospital of Chinese People's Armed Police Forces, Beijing 100039, China.

Received: 10 August 2020 Accepted: 10 December 2020 Published online: 07 January 2021

\section{References}

1. Li Y, Pfeffer MA, Solomon SD, Weinfurt KP, et al. Impact of cardiovascular events on change in quality of life and utilities in patients after myocardial
}

infarction: a VALIANT study (valsartan in acute myocardial infarction). JACC Heart Fail. 2014:2:159-65.

2. Lavall MC, Bagatini MD, Thomé GR, et al. Extracellular hydrolysis of adenine nucleotides and nucleoside adenosine is higher in patients with ST elevation than non-ST elevation in acute myocardial infarction. Clin Lab. 2015;61(7):761-7.

3. Kook HY, Jeong MH, Oh S, et al. Current trend of acute myocardial infarction in Korea (from the Korea Acute Myocardial Infarction Registry from 2006 to 2013). Am J Cardiol. 2014;114(12):1817-22.

4. Gnavi R, Rusciani R, Dalmasso M, et al. Gender, socioeconomic position, revascularization procedures and mortality in patients presenting with STEMI and NSTEMI in the era of primary PCI. Differences or inequities? Int J Cardiol. 2014;176(3):724-30.

5. Kloner RA, Dai W, Hale SL, et al. Approaches to improving cardiac structure and function during and after an acute myocardial infarction:acute and chronic phases. J Cardiovasc Pharmacol Ther. 2016;21(4):363-7.

6. Li J, Li X, Wang Q, Hu S, et al. China PEACE Collaborative Group. ST-segment elevation myocardial infarction in China from 2001 to 2011 (the China PEACE-Retrospective Acute Myocardial Infarction Study): a retrospective analysis of hospital data. Lancet. 2015;385:441-51.

7. Wang S, Marquez P, Langenbrunner J, et al. Toward a healthy and harmonious life in China: stemming the rising tide of non-communicable diseases. World Bank. 2012:1-48.

8. Müllera P, Lemckea H, Davida R. Stem cell therapy in heart diseases - cell types, mechanisms and improvement strategies. Cell Physiol Biochem. 2018; 48:2607-26655

9. Wu R, Hu X, Wang J. Concise review: optimized strategies for stem cellbased therapy in myocardial repair: clinical translatability and potential limitation. Stem Cells. 2018;36:482-500.

10. Gnecchi M, Zhang Z, Ni A, et al. Paracrine mechanisms in adult stem cell signaling and therapy. Circ Res. 2008;103:1204-19.

11. Narita T, Suzuki K. Bone marrow-derived mesenchymal stem cells for the treatment of heart failure. Heart Fail Rev. 2015;20:53-68.

12. Martin-Rendon E, Brunskill SJ, Hyde CJ, et al. Autologous bone marrow stem cells to treat acute myocardial infarction: a systematic review. Eur Heart J. 2008;29:1807-18.

13. Parekkadan B, Milwid JM. Mesenchymal stem cells as therapeutics. Annu Rev Biomed Eng. 2010;12:87-117.

14. Wollert KC, Drexler H. Mesenchymal stem cells for myocardial infarction: promises and pitfalls. Circulation. 2005;112(2):151-3.

15. Ward MR, Abadeh A, Connelly KA. Concise review: rational use of mesenchymal stem cells in the treatment of ischemic heart disease. Stem Cells Transl Med. 2018;7(7):543-50.

16. Ramkisoensing AA, Pijnappels DA, Askar SF, et al. Human embryonic and fetal mesenchymal stem cells differentiate toward three different cardiac lineages in contrast to their adult counterparts. PLoS One. 2011; 6:e24164.

17. Duffy MM, Ritter T, Ceredig R, et al. Mesenchymal stem cell effects on T-cell effector pathways. Stem Cell Res Ther. 2011;2:34.

18. Fan $L, H u C$, Chen J, et al. Interaction between mesenchymal stem cells and B-cells. Int J Mol Sci. 2016:17:E650.

19. Zhang B, Liu R, Shi D, et al. Mesenchymal stem cells induce mature dendritic cells into a novel Jagged-2-dependent regulatory dendritic cell population. Blood. 2009;113:46-57.

20. Langrzyk A, Nowak WN, Stepniewski J, et al. Critical view on mesenchymal stromal cells in regenerative medicine. Antioxid Redox Signal. 2018;29:169-90.

21. Kobayashi K, Suzuki K. Mesenchymal stem/stromal cell-based therapy for heart failure - what is the best source? Circ J. 2018:82(9):2222-32.

22. Strauer BE, Brehm M, Zeus T, et al. Intracoronary, human autologous stem cell ransplantation for myocardial regeneration following myocardial infarction. Dtsch Med Wochen schr. 2001;126(34-35):932-8.

23. Strauer $B E$, Brehm M, Zeus $T$, et al. Repair of infarcted myocardium by autologous intracoronary mononuclear bone marrow cell transplantation in humans. Circulation. 2002;106(15):1913-8.

24. Bartunek J, Wijns W, Heyndrickx GR, et al. Timing of intracoronary bonemarrow-derived stem cell transplantation after ST-elevation myocardial infarction. Nat Clin Pract Cardiovasc Med. 2006;3(Suppl 1):S52-6.

25. Wollert KC, Meyer GP, Müller-Ehmsen J, et al. Intracoronary autologous bone marrow cell transfer after myocardial infarction: the BOOST-2 randomised placebo-controlled clinical trial. Eur Heart J. 2017;38(39):2936-43. 
26. Fan $M$, Chen $W$, Liu W, et al. The effect of age on the efficacy of human mesenchymal stem cell transplantation after a myocardial infarction. Rejuvenation Res. 2010;13(4):429-38.

27. Vulliet PR, Greeley M, Halloran SM, et al. Intra-coronary arterial injection of mesenchymal stromal cells and microinfarction in dogs. Lancet. 2004;363: 783-4.

28. Perin EC, Borow KM, Silva GV, et al. A phase II dose-escalation study of allogeneic mesenchymal precursor cells in patients with ischemic or nonischemic heart failure. Circ Res. 2015;117:576-84.

29. Florea V, Rieger AC, DiFede DL, et al. Dose comparison study of allogeneic mesenchymal stem cells in patients with ischemic cardiomyopathy (The TRIDENT Study). Circ Res. 2017;121:1279-90.

30. Strauer BE, Brehm M, Zeus T. Repair of infarcted myocardium by autologous intracoronary mononuclear bone marrow cell transplantation in humans. Circulation. 2002:106(15):1913-8.

31. Zhang $S$, Sun $A, X u D$, et al. Impact of timing on efficacy and safetyof intracoronary autologous bone marrow stem cells transplantation in acute myocardial infarction: a pooled subgroup analysis of randomized controlled trials. Clin Cardiol. 2009;32(8):458-66.

32. Wang Z, Wang L, Su X, et al. Rational transplant timing and dose of mesenchymal stromal cells in patients with acute myocardial infarction: a meta-analysis of randomized controlled trials. Stem Cell Res Ther. 2017;8(1): 21.

33. Kim SH, Cho JH, Lee YH, et al. Improvement in left ventricular function with intracoronary mesenchymal stem cell therapy in a patient with anterior wall ST-segment elevation myocardial infarction. Cardiovascular Drugs Therapy. 2018:32(4):329-38.

34. Fukushima S, Sawa Y, Suzuki K. Choice of cell-delivery route for successful cell transplantation therapy for the heart. Futur Cardiol. 2013;9:215-27.

35. Tano N, Narita T, Kaneko M, et al. Epicardial placement of mesenchymal stromal cellsheets for the treatment of ischemic cardiomyopathy; in vivo proof-of-concept study. Mol Ther. 2014;22:1864-71.

36. Ichihara Y, Kaneko M, Yamahara K, et al. Self-assembling peptide hydrogel enables instant epicardial coating of the heart with mesenchymal stromal cells for the treatment of heart failure. Biomaterials. 2018;154:12-23.

37. Fukushima S, Varela-Carver A, Coppen SR, et al. Direct intramyocardial but not intracoronary injection of bone marrow cells induces ventricular arrhythmias in a rat chronic ischemic heart failure model. Circulation. 2007; 115(17):2254-61.

38. Kalaszczynska I, Ferdyn K. Wharton's jelly derived mesenchymal stem cells: future of regenerative medicine? Recent findings and clinical significance. Biomed Res Int. 2015;2015:430847.

39. Abbaszadeh H, Ghorbani F, Derakhshani M, et al. Human umbilical cord mesenchymal stem cell-derived extracellular vesicles: a novel therapeutic paradigm. J Cell Physiol. 2020;235(2):706-17.

40. Lopez Y, Lutjemeier B, Seshareddy K, et al. Wharton's jelly or bone marrow mesenchymal stromal cells improve cardiac function following myocardial infarction for more than 32 weeks in a rat model: a preliminary report. Curr Stem Cell Res Ther. 2013;8(1):46-59.

41. Zhang W, Liu XC, Yang L, et al. Wharton's jelly-derived mesenchymal stem cells promote myocardial regeneration and cardiac repair after miniswine acute myocardial infarction. Coron Artery Dis. 2013;24(7):549-58.

42. Marino L, Castaldi MA, Rosamilio R, et al. Mesenchymal stem cells from the Wharton's jelly of the human umbilical cord: biological properties and therapeutic potential. Int J Stem Cells. 2019:12(2):218-26.

43. Kretlow JD, Jin YQ, Liu W, et al. Donor age and cell passage affects differentiation potential of murine bone marrow-derived stem cells. BMC Cell Biol. 2008;9:60

44. Zhang $S$, Sun A, Xu D, et al. Impact of timing on efficacy and safety of intracoronary autologous bone marrow stem cells transplantation in acute myocardial infarction: a pooled subgroup analysis of randomized controlled trials. Clin Cardiol. 2009;32(8):458-66.

\section{Publisher's Note}

Springer Nature remains neutral with regard to jurisdictional claims in published maps and institutional affiliations.

\section{Ready to submit your research? Choose BMC and benefit from:}

- fast, convenient online submission

- thorough peer review by experienced researchers in your field

- rapid publication on acceptance

- support for research data, including large and complex data types

- gold Open Access which fosters wider collaboration and increased citations

- maximum visibility for your research: over $100 \mathrm{M}$ website views per year

At BMC, research is always in progress.

Learn more biomedcentral.com/submissions 